\title{
Editorial
}

\section{O LIMITE ENTRE A EXPERIÊNCIA CLÍNICA E O USO DE TECNOLOGIA EM SAÚDE DA COMUNICAÇÃO HUMANA}

Em um mundo rodeado de inovações tecnológicas a Fonoaudiologia tem cada vez mais buscado introduzir arsenal de equipamentos disponíveis que parecem facilitar a vida do clínico ampliando as possibilidades de um diagnóstico mais preciso.

A busca pela objetividade no diagnóstico leva o profissional da área de comunicação humana a desejar cada vez mais recursos avançados que possibilitem a comprovação do que é observado na avaliação clínica

Em Motricidade Orofacial especialidade que tenho me dedicado a atuar no ensino, pesquisa e extensão, isto não é diferente. Tenho presenciado muitos de nossos acreditando que esta objetividade desejada está depositada no arsenal tecnológico muitas vezes não facilmente acessível.

Caímos no equívoco de caracterizar qualquer procedimento tecnológico como exame objetivo. A experiência nos mostra que estes exames também têm seu nível de subjetividade visto que, a meta do avaliador e as diversas formas de interpretações dos achados são variáveis e devem ser levadas em consideração na conclusão do diagnóstico. Essas considerações precisam ser levadas em conta quando se atribui essa "objetividade" sonhada por todos nós que fazemos a clínica. Na área de Motricidade Orofacial temos recomendado que estes procedimentos sejam denominados de exames quantitativos.

A falta de clareza sobre o uso dos dados coletados durante os exames complementares também é observada. Muitas vezes as medidas resultantes da avaliação antropométrica da face com paquímetro têm aspectos apenas numéricos se não forem associadas com as funções de mastigação e respiração.

A avaliação da atividade elétrica dos músculos envolvidos nos sistemas estomatognático e fonador, obtidos pela eletromiografia de superfície só farão sentido se os dados forem tratados, normalizados e associados com a ação desses músculos no complexo oromiofuncinal e cervical.

O estudo da velocidade e amplitude dos movimentos mandibulares quantificados pela eletrognatografia tem íntima relação com as características clínicas da mastigação e movimentos da mandíbula durante a fala. O ganho clínico para estas funções com o uso desta ferramenta é assertivo.

Embora seja observada a evolução tanto nos procedimentos relacionados ao diagnóstico como nos recursos utilizados em fonoterapia, nunca é demais lembrar que a formação e a experiência do clínico é o aspecto mais importante quando se fala em avaliação e terapia fonoaudiológica. Toda e qualquer tecnologia utilizada nas nossas avaliações deve ser considerada como complementar. Seguindo este caminho não correremos o risco de perder o valor do saber e da experiência do clínico que indiscutivelmente deve ser a base de nossa atuação em Fonoaudiologia.

A ABRAMO - Associação Brasileira de Motricidade Orofacial criada oficialmente durante IV Encontro Brasileiro de Motricidade Orofacial tem dentre outros objetivos levar aos profissionais os avanços tecnológicos em nossa especialidade, mas sobretudo discutir o nosso fazer clínico. As discussões geradas em nosso último encontro nos permitiram presenciar conquistas clínicas em diferentes regiões do país e nos motivou a continuar na grande tarefa de pesquisar em nossa ciência. O prazer de dividir estes conhecimentos e aprender com as discussões geradas em encontros deste nível têm possibilitado um fazer clínico onde as conquistas de nossos clientes podem ser quantificadas e representam as conquistas em nosso campo de atuação.

A Revista CEFAC tem sido uma grande parceira na divulgação dessas conquistas. Os artigos apresentados neste número mostram a diversidade dos temas que estão sendo desenvolvidos em nosso país, bem como a distribuição geográfica dos pesquisadores que dividem aqui os conhecimentos oriundos de suas pesquisas.

A área de Linguagem apresenta neste volume 06 artigos dos Estados de São Paulo, Minas Gerais e Rio Grande do Sul. As pesquisas relacionadas à fonologia e leitura e escrita são bem representadas.

Pesquisadores do Rio Grande do Sul, São Paulo e do Chile apresentam os resultados de seus trabalhos com temas em Fissuras Labiopalatinas, neonatologia e mastigação trazendo avanços na especialidade Motricidade Orofacial. 
A preocupação em traçar valores de normalidade, caracterizar habilidades auditivas, estudar fatores que envolvem a adaptação de próteses auditivas e o processamento auditivo estão presentes nas 06 pesquisas apresentadas na área de Audiologia de autores dos estados de São Paulo e Rio Grande do Sul.

A área de Voz traz resultados de pesquisa com avaliação objetiva e subjetiva e de estudo com voz do professor além de um artigo de revisão sobre lesões organofuncionais também dos estados de São Paulo, Minas Gerais e Rio Grande do Sul.

Em Saúde Coletiva autores do estado de Minas Gerais apresentam resultados de pesquisa sobre conhecimento e instrumentalização de professores sobre o desenvolvimento de fala.

Os trabalhos aqui apresentados refletem que o uso de tecnologia, o conhecimento aprofundado do desenvolvimento normal, fisiopatológico e dos processos clínicos de avaliação e o tratamento são caminhos para o desenvolvimento de nossa ciência.

Boa Leitura!

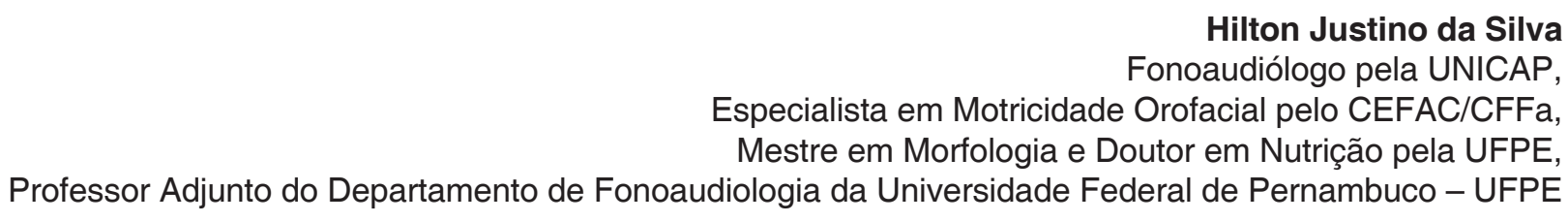

